\author{
Doug Campos-Outcalt, \\ MD, MPA \\ University of Arizona, \\ Phoenix \\ Ddougco@email.arizona. \\ edu \\ doi: $10.12788 / \mathrm{jfp} .0079$

\section{Prospects and challenges for the upcoming influenza season} \\ New vaccine and antiviral products are available, and \\ additional vaccine contraindications are identified. The \\ concurrence of influenza and SARS-coV-19 could create \\ synergies for preventive care.
}

$\mathrm{T}$ he 2020-2021 influenza season is shaping up to be challenging. Its likely concurrence with the ongoing severe acute respiratory syndrome-coronavirus 2 (SARS-coV-2) pandemic (COVID-19) will pose diagnostic and therapeutic dilemmas and could overload the hospital system. But there could also be potential synergies in preventing morbidity and mortality from each disease.

\section{A consistent pattern over}

\section{the past few influenza seasons}

During the 2019-2020 flu season, there were an estimated 410,000 to 740,000 hospitalizations and 24,000 to 62,000 deaths attributed to influenza. ${ }^{1}$ As seen in FIGURE 1, office visits for influenza-like illness (ILI) began to increase in late November and early December in each of the last 3 years (2017-2018, 2018-2019, 2019-2020) and stayed elevated above baseline for about 4 months each season. ${ }^{1}$

The effectiveness of influenza vaccine during the 2019-2020 season is being estimated using the US Flu Vaccine Effectiveness Network, which has close to 9000 enrollees. Overall, it appears the vaccine was $39 \%$ effective against medically attended influenza, with a higher effectiveness against influenza B (44\%) than against A/H1N1 (31\%). Effectiveness against influenza $B$ was similar in all age groups, but effectiveness against $\mathrm{A} / \mathrm{H} 1 \mathrm{~N} 1$ was highest for those ages 50 to 64 years (45\%) and lowest for those ages 6 months through 8 years
(22\%), although 95\% confidence intervals overlapped for all age groups (FIGURE 2). These preliminary effectiveness rates were presented at the summer meeting of the Advisory Committee on Immunization Practices (ACIP). ${ }^{1}$

Influenza vaccine safety data for 2019-2020 were based on the Vaccine Adverse Event Reporting System (VAERS), a passive surveillance system, and on the Vaccine Safety Datalink (VSD) system, an active surveillance system involving close to 6 million doses administered at VSD sites. No safety concerns were identified for any of the different vaccine types. Both the VAERS and VSD surveillance systems have been described in more detail in a previous Practice Alert. ${ }^{2}$

\section{Recommendations for 2020-2021}

The composition of the influenza vaccines for this year's flu season will be different for 3 of the 4 antigens: A/H1N1, A/H2N2 and B/Victoria. ${ }^{3}$ The antigens included in the influenza vaccines each year are decided on in the spring, based on surveillance of circulating strains around the world. The effectiveness of the vaccine each year largely depends on how well the strains included in the vaccine match those circulating in the United States during the influenza season.

- The main immunization recommendation for preventing morbidity and mortality from influenza has not changed: All individuals ages 6 months and older without a contraindication should receive an influenza 


\section{FIGURE 1}

\section{Similarity of ILI patterns over the past}

\section{3 flu seasons ${ }^{1}$}

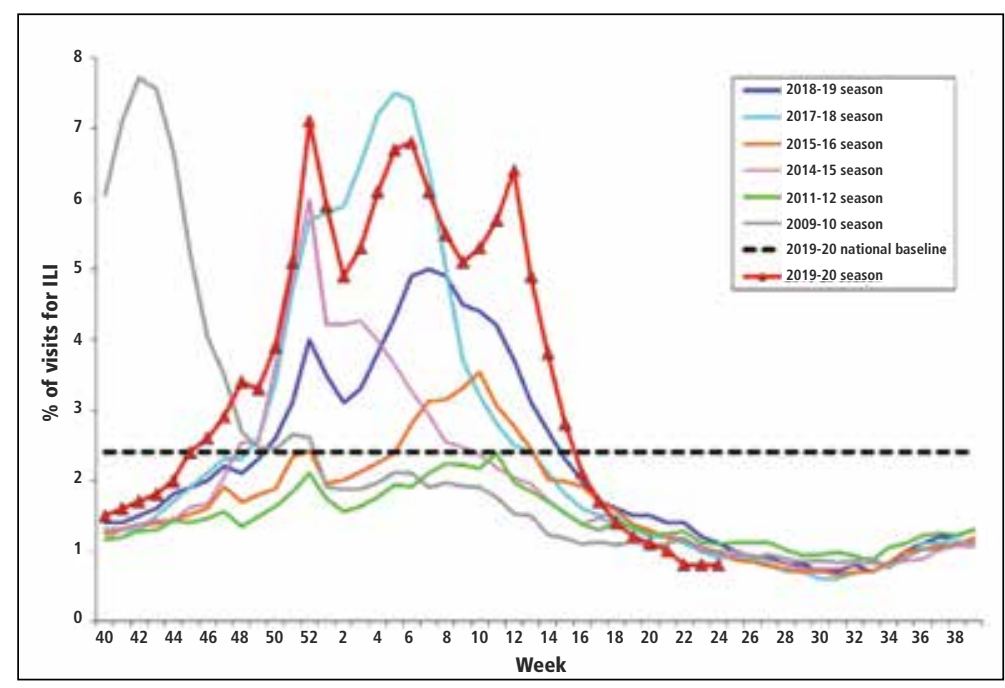

Office visits for ILI began increasing in late November and early December in each of the past 3 seasons $(2017-2018,2018-2019,2019-2020)$ and stayed elevated above baseline for about 4 months.

ILI, influenza-like illness.

\section{FIGURE 2}

\section{Effectiveness of influenza vaccine}

\section{against A/H1N1 in 2019-2020 season ${ }^{1}$}

Last year's flu vaccine was most effective against $\mathrm{A} / \mathrm{H} 1 \mathrm{~N} 1$ in individuals ages 50 to 64 years and least effective in those ages 6 months to 8 years.

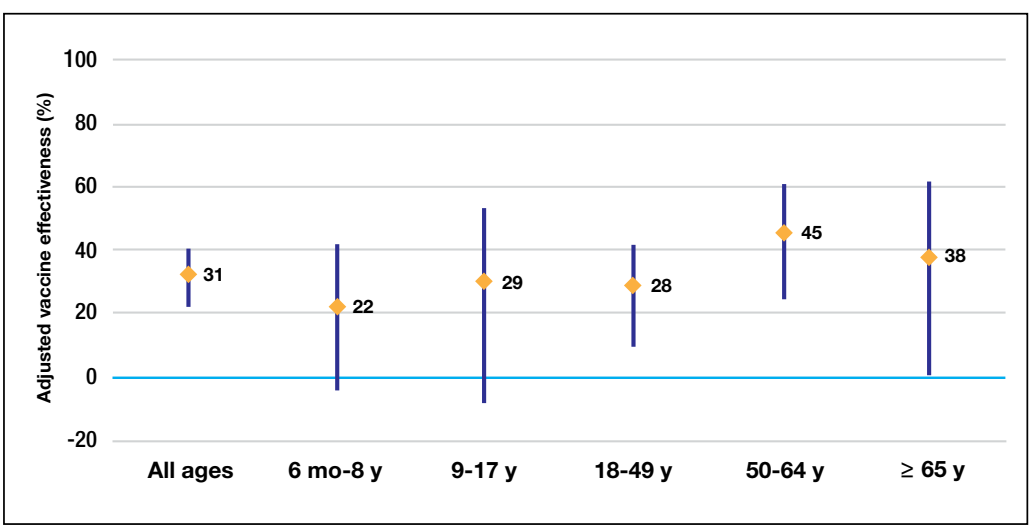

vaccine. ${ }^{4}$ The Centers for Disease Control and Prevention (CDC) recommends that patients receive the vaccine by the end of October. ${ }^{4}$ This includes the second dose for those children younger than 9 years who need 2 doses-ie, those who have received fewer than 2 doses of influenza vaccine prior to July 2020 . Vaccination should continue through the end of the season for anyone who has not received a 2020-2021 influenza vaccine.

I Two new influenza vaccine products are available for use in those ages 65 years and older: Fluzone high-dose quadrivalent and Fluad Quadrivalent (adjuvanted). ${ }^{4}$ Both of these products were available last year as trivalent options. Currently no specific vaccine product is listed as preferred by ACIP for those ages 65 and older.

I New vaccine contraindications. Four medical conditions have been added to the list of contraindications for quadrivalent live, attenuated influenza vaccine (LAIV4): cochlear implant, cerebrospinal fluid leak, asplenia (anatomic and functional), and sickle cell anemia. ${ }^{4}$ In addition, those who receive LAIV4 should not be prescribed an influenza antiviral until 2 weeks after receiving the vaccine. And the vaccine should not be administered for 48 hours after receipt of oseltamivir or zanamivir, 5 days after peramivir, and 17 days after baloxavir marboxil. ${ }^{4}$ This is to prevent possible antiviral inactivation of the live attenuated influenza viruses in the vaccine.

I For those who have a history of severe allergic reaction to eggs, there are now 2 egg-free options: cell-culture-based inactivated vaccine (ccIIV4) and recombinant influenza vaccine (RIV4) ${ }^{3,4}$ Urticaria alone is not considered a severe reaction. If neither of these egg-free options is available, a vaccine may still be administered in a medical setting supervised by a provider who is able to manage a severe allergic reaction (which rarely occurs).

All vaccine products available for the upcoming influenza season are listed and described on the CDC Web site, as is a summary of related recommendations. ${ }^{4}$ Particular attention should be paid to the dose of vaccine administered, as it differs by product for those ages 6 through 35 months of age and those ages 65 years and older.

\section{Use of antiviral medications}

Four antiviral medications are now available for treating influenza (3 neuraminidase inhibitors and 1 endonuclease inhibitor), and there are 2 agents for preventing influenza, both neuraminidase inhibitors (TABLE 1). ${ }^{5}$ The CDC recommends treating with antivirals as soon 
TABLE 1

Recommended dosages and duration of influenza antiviral medications for treatment or chemoprophylaxis ${ }^{5}$

\begin{tabular}{|c|c|c|c|}
\hline Agent & Use & Children & Adults \\
\hline \multirow[t]{2}{*}{$\begin{array}{l}\text { Oral } \\
\text { oseltamivir }\end{array}$} & $\begin{array}{l}\text { Treatment } \\
\text { (5 days) }\end{array}$ & $\begin{array}{l}\text { If }<1 \mathrm{yr}: 3 \mathrm{mg} / \mathrm{kg} / \text { dose twice daily } \\
\text { If } \geq 1 \mathrm{yr} \text {, dose varies by child's weight: } \\
\leq 15 \mathrm{~kg} \text {, dose is } 30 \mathrm{mg} \text { twice a day } \\
>15 \text { to } 23 \mathrm{~kg} \text {, dose is } 45 \mathrm{mg} \text { twice a day } \\
>23 \text { to } 40 \mathrm{~kg} \text {, dose is } 60 \mathrm{mg} \text { twice a day } \\
>40 \mathrm{~kg} \text {, dose is } 75 \mathrm{mg} \text { twice a day }\end{array}$ & 75 mg twice daily \\
\hline & $\begin{array}{l}\text { Chemoprophylaxis } \\
\text { (7 days) }\end{array}$ & $\begin{array}{l}\text { If }<3 \text { months, use of oseltamivir for chemoprophylaxis } \\
\text { is not recommended unless situation is judged critical } \\
\text { If } \geq \mathbf{3} \text { months and }<1 \mathrm{yr}, 3 \mathrm{mg} / \mathrm{kg} / \text { dose once daily } \\
\text { If } \geq 1 \mathrm{yr} \text {, dose by weight: } \\
\leq 15 \mathrm{~kg} \text {, dose is } 30 \mathrm{mg} \text { once a day } \\
>15 \text { to } 23 \mathrm{~kg} \text {, dose is } 45 \mathrm{mg} \text { once a day } \\
>23 \text { to } 40 \mathrm{~kg} \text {, dose is } 60 \mathrm{mg} \text { once a day } \\
>40 \mathrm{~kg} \text {, dose is } 75 \mathrm{mg} \text { once a day }\end{array}$ & 75 mg once daily \\
\hline \multirow[t]{2}{*}{$\begin{array}{l}\text { Inhaled } \\
\text { zanamivir }\end{array}$} & $\begin{array}{l}\text { Treatment } \\
\text { (5 days) }\end{array}$ & $\begin{array}{l}10 \mathrm{mg} \text { (two } 5-\mathrm{mg} \text { inhalations) twice daily } \\
\text { (FDA approved and recommended for use in children } \\
\geq 7 \mathrm{yrs} \text { ) }\end{array}$ & $\begin{array}{l}10 \mathrm{mg} \text { (two 5-mg } \\
\text { inhalations) twice daily }\end{array}$ \\
\hline & $\begin{array}{l}\text { Chemoprophylaxis } \\
\text { (7 days) }\end{array}$ & $\begin{array}{l}10 \mathrm{mg} \text { (two } 5-\mathrm{mg} \text { inhalations) once daily } \\
\text { (FDA approved and recommended for use in children } \\
\geq 5 \mathrm{yrs} \text { ) }\end{array}$ & $\begin{array}{l}10 \mathrm{mg} \text { (two 5-mg } \\
\text { inhalations) once daily }\end{array}$ \\
\hline \multirow[t]{2}{*}{$\begin{array}{l}\text { Intravenous } \\
\text { peramivir }\end{array}$} & $\begin{array}{l}\text { Treatment } \\
\text { (1 day) }\end{array}$ & $\begin{array}{l}\text { 2-12 yrs: One } 12 \mathrm{mg} / \mathrm{kg} \text { dose, up to } 600 \mathrm{mg} \text { maximum, } \\
\text { via intravenous infusion for a minimum of } 15 \text { minutes } \\
\text { (FDA approved and recommended for use in children } \\
\geq 2 \mathrm{yrs} \text { ) }\end{array}$ & $\begin{array}{l}\text { ( } \geq 13 \text { yrs) one } 600 \mathrm{mg} \text { dose, } \\
\text { via intravenous infusion for a } \\
\text { minimum of } 15 \text { minutes }\end{array}$ \\
\hline & Chemoprophylaxis & Not recommended & N/A \\
\hline \multirow[t]{2}{*}{$\begin{array}{l}\text { Oral } \\
\text { baloxavir }\end{array}$} & $\begin{array}{l}\text { Treatment } \\
\text { (1 day) }\end{array}$ & $\begin{array}{l}\text { FDA approved and recommended for use in children } \\
\geq 12 \text { yrs weighing at least } 40 \mathrm{~kg} \text {. (See adult dosage.) }\end{array}$ & $\begin{array}{l}\text { ( } \geq 12 \text { yrs) } 40 \text { to }<80 \mathrm{~kg}: \text { one } 40 \\
\mathrm{mg} \text { dose; } \geq 80 \mathrm{~kg}: \text { one } 80 \mathrm{mg} \\
\text { dose }\end{array}$ \\
\hline & Chemoprophylaxis & Not recommended & N/A \\
\hline
\end{tabular}

N/A, not approved.

as possible if individuals with confirmed or suspected influenza require hospitalization; have severe, complicated, or progressive illness; or are at high risk for complications. Use antivirals based on clinical judgment if previously healthy individuals do not have severe complications and are not at increased risk for complications, and only if the medication can be started within 48 hours of symptom onset.

The CDC discourages widespread use of antivirals to prevent influenza, either pre- or postexposure, although it specifies certain situations in which usage would be acceptable (TABLE 2). ${ }^{5}$ There is some concern that widespread use could lead to the emergence of drug-resistant strains and that using postexposure dosing could lead to suboptimal treat- ment if influenza infection occurred before the start of prophylaxis. If postexposure antivirals are prescribed, they should be started within 48 hours of exposure and continued for 7 days after the last exposure.

\section{A potential perfect storm: Concurrence of influenza and SARS-coV-19}

While we have vaccines and antivirals to prevent influenza, and have effective antivirals for treatment, no prevention or treatment options exist for COVID-19, except, possibly, dexamethasone to reduce mortality among those seriously ill. ${ }^{6}$ The concurrence of influenza and COVID-19 will present unique challenges for the health care system.

I Action steps. Keep abreast of the in- 
TABLE 2

\section{Possible use of antiviral medications for influenza prevention ${ }^{5 a}$}

- Controlling institutional influenza outbreaks, as part of a multiinterventional approach

- Preventing influenza in people at high risk of influenza complications during the first 2 weeks following vaccination after exposure to a person with influenza

- Preventing complications after exposure to influenza, for individuals at high risk who cannot receive influenza vaccine due to a contraindication

- Preventing complications after exposure to influenza, for those with severe immune deficiencies or those who might not respond to influenza vaccination, such as individuals receiving immunosuppressive medications

a Patients receiving antiviral chemoprophylaxis should be encouraged to seek medical evaluation as soon as they develop a febrile respiratory illness that might indicate influenza.
- All household members should be vaccinated against influenza. Those who are unvaccinated, and those at high risk who have been recently vaccinated, can consider influenza antiviral prophylaxis. If the sick family member is confirmed to have COVID-19, with no co-existing influenza, anti-influenza antiviral prophylaxis may be discontinued.

- Clinical infection control practices should be the same for anyone presenting with ILI. ${ }^{7}$ Enhanced clinic-based infection control practices to prevent spread of SARS-CoV-2 are listed in TABLE $3{ }^{8}$

Since there currently are no preventive medications proven to work for COVID-19, the main clinical decision physicians will have to make when a patient presents with ILI is whether to use antivirals to treat those who are at risk for complications based on the result of rapid, on-site influenza testing, or clinical presentation, or both. In this situation, knowledge of which viruses are circulating at high rates in the community could be valuable.

Milder season or perfect storm? The society-wide interventions that have been encouraged (although not mandated everywhere) to prevent community spread of SARS-CoV-2 should help prevent the community spread of influenza as well, and, if adhered to, may lead to a milder influenza season than would otherwise have occurred. However, given the uncertainties, the combination of influenza and coronavirus could present a perfect storm for the health care system and result in higher-than-normal morbidity and mortality from ILI and pneumonia overall.

The possibility that one or more vaccines to prevent COVID-19 may be available in late 2020 or early 2021 offers hope. However, in current testing, the vaccine is not being given simultaneously with the influenza vaccine. If the potential for adverse interaction exists between the vaccines, it is important that influenza vaccine be given by mid- to late-October to avoid such an interaction if and when the new SARS-CoV-2 vaccine becomes available. Individuals who have symptoms of COVID-19 should not be vaccinated with influenza vaccine until they are considered noninfectious. 
TABLE 3

\section{Clinic policies to limit the spread of SARS-CoV-2 ${ }^{8}$}

- Screen patients for COVID-19 symptoms before and during the visit.

- Require physical distancing (at least 6 feet apart) where possible.

- Limit and monitor facility points of entry and install barriers to limit physical contact with patients at triage.

- Promote respiratory hygiene (face masks for staff and face coverings for patients $>2 \mathrm{yrs}$, if tolerated) and cough etiquette.

- Urge hand hygiene, providing at least $60 \%$ alcohol hand sanitizer for patients.

- Use enhanced surface decontamination. COVID-19, coronavirus disease of 2019; SARS-CoV-2, severe acute respiratory syndrome-coronavirus-2.

I Encourage influenza vaccination. The COVID-19 pandemic may make it difficult to achieve desired community influenza vaccine levels because of decreased visits to medical facilities for preventive care, possible lower insurance coverage due to loss of employment, and a decrease in worksite mass vaccination programs. This makes it important for family physicians to encourage and offer influenza vaccines at their clinical sites.

Several evidence-based practices have been shown to improve vaccine uptake. Examples of such practices include patient reminder and recall systems that provide feedback to clinicians about rates of vaccination among patients, and establishing standing orders for vaccine administration that allow other health care providers to assess a patient's immunization status and administer vaccinations according to a protocol. ${ }^{9}$ Finally, the CDC provides a video on how to recommend influenza vaccine to those who may be resistant (www. cdc.gov/vaccines/howirecommend/adultvacc-videos.html).

\section{CDC influenza} resources

Point-of-care tests that detect both influenza $A$ and $B$ viruses approved by the CDC

www.cdc.gov/flu/professionals/diagnosis/ table-ridt.html

Advice on how to interpret the test results

www.cdc.gov/flu/professionals/diagnosis/ clinician_guidance_ridt.htm

How to recommend influenza vaccine to reluctant patients

www.cdc.gov/vaccines/howirecommend/ adult-vacc-videos.html

CDC, Centers for Disease Control and Prevention.

References

1. Grohskopf L. Influenza work groups: updates, considerations, and proposed recommendations for the 2020-2021 season. Presented at the ACIP meeting June 24, 2020. www.youtube.com/watch?v= W1SV2DSJsaQ\&list=PLvrp9iOILTQb6D9elYZWpbUvzfptNMKx2 \&index $=8 \& \mathrm{t}=0 \mathrm{~s}$. [Time stamp: 1:26:48] Accessed Septemeber 29, 2020.

2. Campos-Outcalt D. Facts to help you keep pace with the vaccine conversation. J Fam Pract. 2019;68:341-346.

3. Grohskopf L, Alyanak E, Broder KR, et al. Prevention and control of seasonal influenza with vaccines: recommendations of the Advisory Committee on Immunization Practices-United States, 202021 Influenza Season. MMWR Recomm Rep. 2020;69:1-24.

4. Prevention and Control of Seasonal Influenza with Vaccines: Recommendations of the Advisory Committee on Immunization Practices (ACIP)-United States, 2020-21 Summary of Recommendations. www.cdc.gov/flu/pdf/professionals/acip/acip2020-21-summary-of-recommendations.pdf. Accessed September 29, 2020.

5. CDC. Influenza antiviral medications: summary for clinicians. www.cdc.gov/flu/professionals/antivirals/summary-clinicians. $\mathrm{htm}$. Accessed September 29, 2020.

6. NIH. COVID-19 treatment guidelines. Corticosteroids. www. covid19treatmentguidelines.nih.gov/immune-based-therapy/ immunomodulators/corticosteroids/. Accessed September 29, 2020.

7. CDC. Infection control. www.cdc.gov/infectioncontrol/. Accessed September 29, 2020

8. CDC. Interim infection prevention and control recommendations for healthcare personnel during the coronavirus disease 2019 (COVID-19) pandemic. www.cdc.gov/coronavirus/2019-ncov/hcp/ infection-control.html. Accessed September 29, 2020.

9. HHS. CPSTF findings for increasing vaccination. www. thecommunityguide.org/content/task-force-findings-increasing vaccination. Accessed September 29, 2020.

\section{(2) Visit us @ mdedge.com/familymedicine

